\title{
Autoimmune chronic active hepatitis (lupoid hepatitis) and primary sclerosing cholangitis in two young adult females
}

Gerald Y. Minuk, MD, FRCP(C), Lloyd R. Sutherland, MD, FRCP(C), S. Chris PAPPAs, MD, FRCP(C), JAMES K. Kelly, MD, FRCP(C), Sue E. Martin, MD

\begin{abstract}
Autoimmune chronic active hepatitis (CAH) and primary sclerosing cholangitis (PSC) are chronic diseases of the hepatobiliary system that have many clinical, immunologic and genetic features in common. Despite these similarities, there are few reports of the two diseases coexisting. Two young women with clinical, biochemical, serologic, radiologic and histologic findings compatible with both autoimmune $\mathrm{CAH}$ and PSC are described. The observation that there may be a striking overlap in the features of these two diseases and recent improvements in diagnostic imaging of the biliary tract suggest that the association of these two diseases in the same individual may be more common than is presently appreciated. Can J Gastroenterol $1988 ; 2(1): 22-27$
\end{abstract}

Key Words: Autoimmune chronic active hepatitis, Inflammatory bowel disease, Primary sclerosing cholangitis.

Department of Medicine, University of Calgary, Calgary, Alberta, Canada and Liver Disease Section, Digestive Diseases Branch NIADDK, National Institutes of Health, Bethesda, Maryland, USA

Correspondence: Dr Gerald Y. Minuk, Liver Diseases Unit - H604, University of Manitoba, Health Sciences Centre, 820 Sherbrook Street, Winnipeg, Manitoba R3A $1 R 9$

Received for publication October 1987. Accepted December 1987
T UPOID OR AUTOIMMUNE CHRONic active hepatitis (CAH) and primary sclerosing cholangitis (PSC) are chronic diseases of the hepatobiliary system that have many features in common. Both diseases affect young adults and frequently progress to cirrhosis and death from liver failure (1. 6). Each is marked by hypergammaglobulinemia $(5,7)$, elevated levels of immune complex-like activity $(8,9)$ and the presence of autoantibodies (5, 10-13). Patients with both disorders have an increased incidence of other 'autoimmune' diseases including inflammatory bowel disease (2, 13-16). Sixty to $80 \%$ of patients with autoimmune CAH or PSC are HLA B8 positive, whereas only $20 \%$ of the general 
antibody was now positive at a 1:1280 titre. Hypergammaglobulinemia was also present. A repeat liver biopsy revealed chronic active hepatitis (Figure 2). ERCP revealed further progression of the previous bile duct lesions. The patient was started on corticosteroids which unmasked diabetes mellitus requiring the addition of insulin. Although the patient improved subjectively while on corticosteroids, biochemical improvement was only transient.

Currently the patient is on prednisone $20 \mathrm{mg}$ daily. Bilirubin is 44 $\mu \mathrm{mol} / \mathrm{L}$ (normal 2 to 18 ); alkaline phosphatase $285 \mathrm{iu} / \mathrm{L}$; and AST 464 $\mathrm{iu} / \mathrm{L}$. Antimitochondrial antibody remains negative, antismooth muscle antibody positive (1:1280), and antinuclear factor positive (1:1280, diffuse pattern).

\section{CASE TWO}

An 18-year-old female presented in January 1975 with a six month history of amenorrhea and excessive fatigue. For several weeks her urine had been dark and her stools pale. On physical examination she was found to be icteric and to have multiple spider angiomas over her head and neck, and palmar erythema. Hepatosplenomegaly was present. Laboratory investigations revealed moderate pancytopenia, elevated serum alanine aminotransferase $180 \mathrm{iu} / \mathrm{L}$ (normal, less than 36), alkaline phosphatase $690 \mathrm{iu} / \mathrm{L}$, and hypergammaglobulinemia. Antinuclear and antismooth muscle antibodies were both present in the serum (titre equal to or more than 1:80) but antimitochondrial antibodies were not detected. The patient's HLA haplotype was B8. Hepatitis B surface antigen ( $\mathrm{HBs} \mathrm{Ag}$ ) was negative by radioimmunoassay. Serum $\propto_{1}$ antitrypsin, ferritin, copper and ceruloplasmin levels were within normal limits. The patient had received no medication and did not abuse alcohol. Family history was negative for chronic liver disease but positive for hypothyroidism and juvenile onset diabetes in her mother and sister, respectively. Significant thrombocytopenia and a prolonged pro-

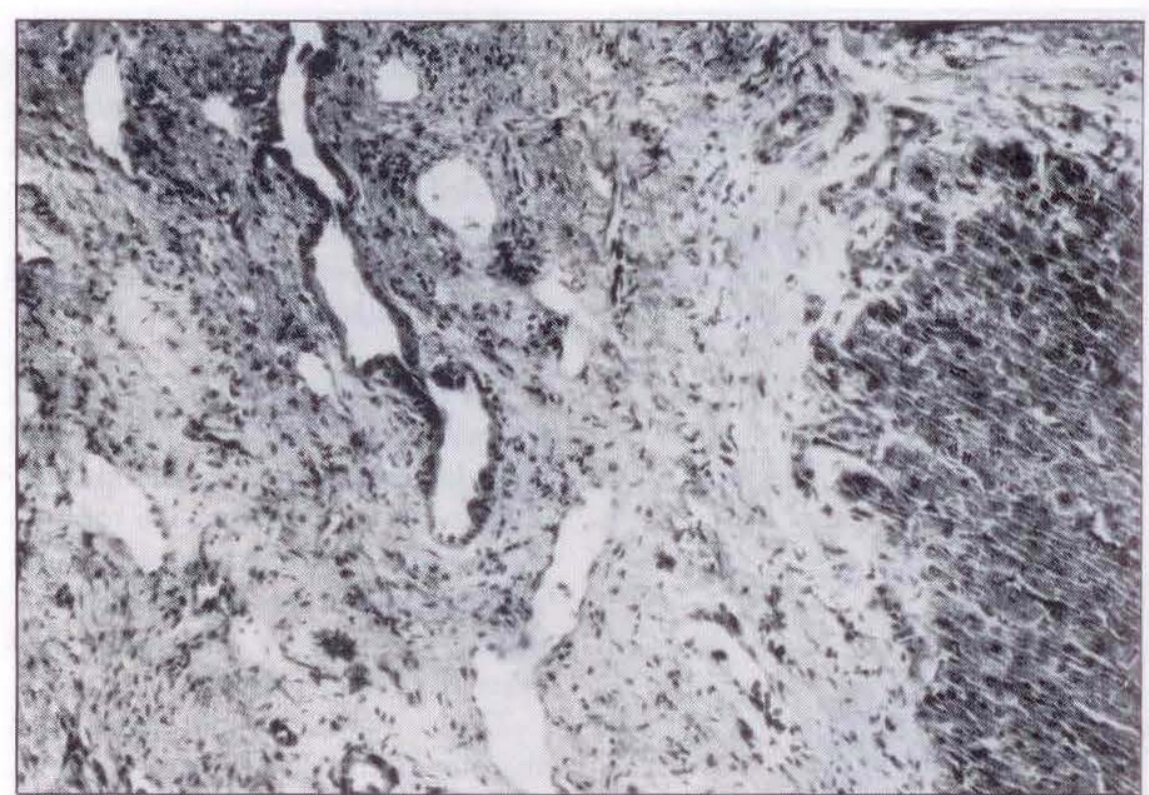

Figure 3) Sections of liver from case two showing micronodular cirrhosis with extension of the portal inflammatory reaction into adjacent hepatic parenchyma. (Hematoxylin and eosin $\times 100$ )

thrombin time precluded a percutaneous liver biopsy.

A tentative diagnosis of autoimmune $\mathrm{CAH}$ was made and the patient was started on prednisone $40 \mathrm{mg}$ /day. With initiation of therapy the patient's symptoms resolved and serum aminotransferase levels fell to within normal limits. Serum alkaline phosphatase levels, however, remained elevated at four to five times the upper limit of normal. A percutaneous liver biopsy, nine months later, revealed cirrhosis with areas of piecemeal necrosis of hepatocytes (Figure 3).

One year following presentation the patient complained of vague abdominal pains and diarrhea. Radiology of the gastrointestinal tract failed to demonstrate any mucosal abnormalities. Serum alkaline phosphatase was still elevated at $517 \mathrm{iu} / \mathrm{L}$. An intravenous cholangiogram demonstrated normal filling of the right, left and proximal common bile duct and a gall bladder that was free from stones. The distal common bile duct was not well visualized.

In January 1977, approximately two years following the initial presentation, the patient developed recurrent hematemesis from ruptured gastroesophageal varices. A distal sple-

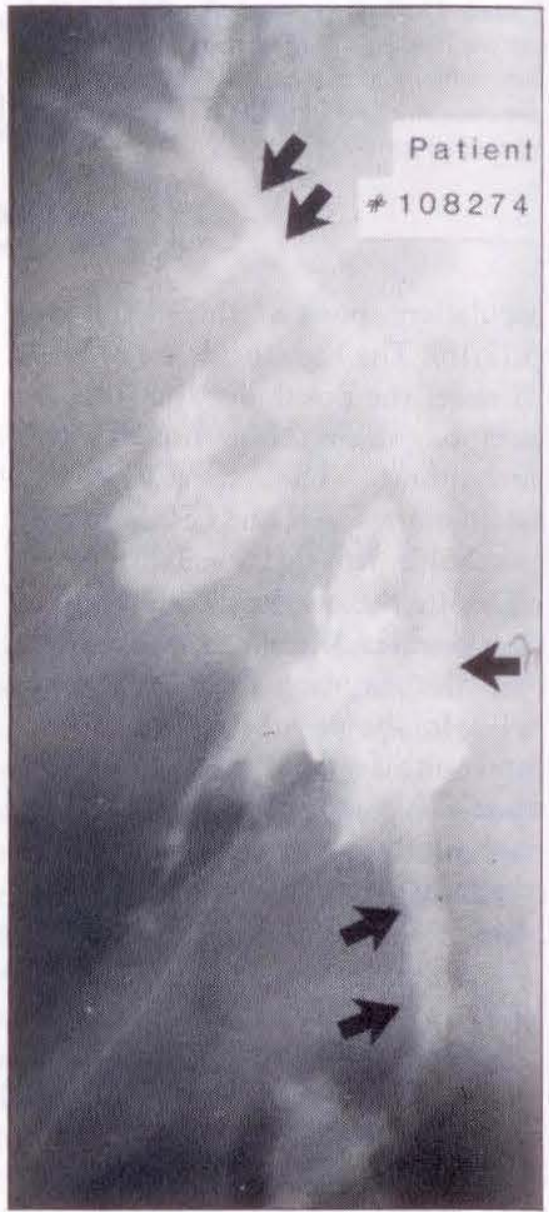

Figure 4) Intraoperative cholangiogram from case two showing multiple areas of stricturing (arrows) with only slight proximal ductal dilatation 
norenal shunt was performed. A wedge biopsy of the liver confirmed the presence of cirrhosis with no portal tract features of chronic biliary disease. Following surgery the patient experienced intermittent abdominal cramps and diarrhea. In June 1977 acute pancreatitis developed with an elevation in serum amylase activity. An oral cholecystogram later revealed multiple small radiolucent stones within the gall bladder.

In February 1978 a cholecystectomy was performed. During this surgery the common bile duct was felt and considered to be thickened and fibrotic. An operative cholangiogram revealed multiple strictures of the common bile duct. Proximal to the strictures there was only slight dilatation of the duct (Figure 4). Following surgery intermittent abdominal cramps and diarrhea persisted. In October 1980, she developed severe right upper quadrant pain, fever and chills.

Cholangiograms performed during the subsequent hospitalization revealed multiple strictures and dilatations of untrahepatic and extrahepatic bile ducts as well as multiple stones throughout the biliary tree. Subsequently, pigmented stones were recurrently extracted using nonsurgical techniques. During the course of a biliary drainage procedure (choledochojejunostomy) in December 1980, a third liver biopsy and a biopsy of the common bile duct were obtained. The liver biopsy revealed cirrhosis, nonsuppurative fibrous cholangitis (Figure 5), and the wall of the common bile duct contained dense bands of fibrous tissue compatible with, but not specific for, primary sclerosing cholangitis.

The patient ultimately was discharged with silastic irrigation catheters placed in both the right and the left hepatic ducts. Six months later (seven years following initial presentation) there was an exacerbation of abdominal cramps and diarrhea. Colonoscopy at that time revealed definite mucosal abnormalities in the left colon and multiple biopsies of the involved area revealed crypt abscess formation with accompanying polymorphonuclear leukocyte and round cell infiltration, changes typical of ulcerative colitis. Long term oral sulfasalazine therapy was prescribed for the colitis.

\section{DISCUSSION}

Autoimmune $\mathrm{CAH}$ is a disease that predominantly affects young females in their second or third decade of life with a second peak in women over the age of 45 . Fatigue, nausea and, in the younger age group, amenorrhea are the most common presenting complaints. On physical examination jaundice and an enlarged liver and spleen may be found. Initial laboratory investigations typically reveal mild pancytopenia, elevated serum levels of aminotransferases and hypergammaglobulinemia. Eighty-five percent of patients will be antinuclear antibody positive, and $80 \%$ antismooth muscle antibody positive (10). If blood clotting tests permit, a severe chronic aggressive hepatitis, or active cirrhosis will be seen on liver biopsy $(7,19)$. The characteristic histologic feature of autoimmune $\mathrm{CAH}$ is active piecemeal necrosis of periportal hepatocytes $(3,20)$. The two patients presented in this report possessed many of the above features. In addition, clinical and serum biochemical indices of the liver disease responded satisfactorily to steroids, a finding entirely consistent with a diagnosis of autoimmune $\mathrm{CAH}$ (21).

As demonstrated by these two cases, confirming the diagnosis of both autoimmune $\mathrm{CAH}$ and PSC in the same patient can be very difficult. It was particularly difficult to establish the additional diagnosis of PSC in case two. By definition, the diagnosis of PSC should not be made in individuals who have had previous surgery on the biliary tract, documented stones in the intrahepatic or extrahepatic biliary tree, or in individuals who have been followed for an insufficient period of time to rule out a malignancy of the biliary tract $(22,23)$. Complications of biliary surgery, cholelithiasis and cholangiocarcinoma can each lead to the development of a syndrome with clinical, radiological and pathological features that are indistinguishable from that of PSC.

Although patient two had surgical exploration of the common bile duct

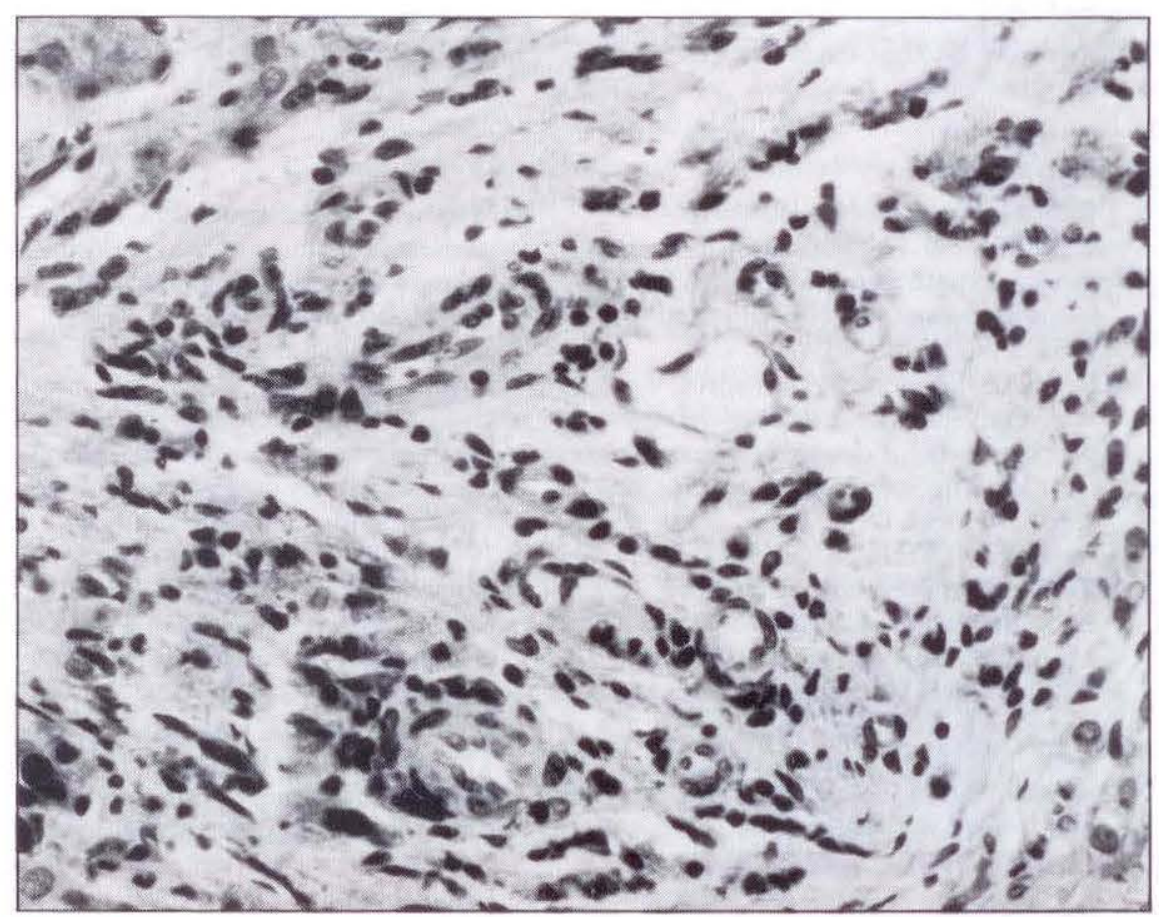

Figure 5) The wedge biopsy of liver from case two showing nonsuppurative fibrous cholangitis, obliteration of bile ducts and marked periportal bile stasis with focal aggregates of acute inflammation. (Hematoxylin and eosin $\times 100$ ) 
and intrahepatic stones documented by cholangiography, it is necessary to consider the timing of these events in relation to the patient's overall course. At the time of initial presentation, three years prior to common duct surgery and five years prior to the demonstration of intrahepatic lithiasis, serum alkaline phosphatase level was already six times the upper limit of normal and remained markedly elevated, being unaltered by the initiation of corticosteroids. Moreover, the first accurate radiologic examination of the patient's biliary tract (performed at the time of cholecystectomy and thus just prior to exploration of the common bile duct and two years prior to intrahepatic stone formation) demonstrated strictures of the proximal common hepatic duct, the right and left hepatic ducts and smaller intrahepatic radicles. Finally, the histologic extent of the sclerosing process seen in the $1980 \mathrm{bi}$ opsy of the common bile duct and the subsequent documentation of chronic idiopathic ulcerative colitis are additional findings supporting a diagnosis of PSC in this patient $(12,26)$.

There are several possible explanations why PSC has not previously been described in patients with autoimmune $\mathrm{CAH}$ and vice versa. One major reason may be that each of these dis-

\section{REFERENCES}

1. Bartholomew LG, Hagedorn AB, Cain JC, et al. Hepatitis and cirrhosis in women with positive clot tests for lupus erythematosis. $\mathrm{N}$ Engl J Med 1958; 259: 947.56.

2. Read AE, Sherlock S, Harrison CV. Active juvenile cirrhosis considered as part of a systemic disease and the effects of corticosteroid therapy. Gut $1963 ; 4: 378-93$.

3. Reynolds TB, Edmonson HE, Peters RL, Redeker AG. Lupoid hepatitis. Ann Int Med 1964; 61: 650-66.

4. Mistilis SP, Skyring AP, Blackburn CRB. Natural history of active chronic hepatitis. 1. Clinical features, course, diagnostic criteria, morbidity, mortality and survival. Aust Ann Med 1968; 17: 214-23.

5. Chapman RWG, Arborgh BM, Rhodes JM, et al. Primary sclerosing cholangitis. review of clinical, cholangiography and hepatic histology. Gut 1980; 21: 870-7. eases has until recently been associated with a relatively short median survival time (autoimmune CAH 3.3 years [27]; PSC 6 years [28]). Thus the likelihood of a second disease appearing during the relatively brief course of the primary one was quite remote. Prolongation of survival of patients with autoimmune $\mathrm{CAH}$ with corticosteroids (23) and improvements in ability to diagnose PSC at an earlier stage (through the advent of multichannel biochemical testing of serum and more accurate biliary imaging techniques) (5) have extended the known survival period for both diseases, thereby enhancing the likelihood of both diseases being detected in the same individual.

A second reason, and one that is particularly relevant to case two, involves the incidence of hepatic stone formation in patients with hepatic cirrhosis. Many patients with autoimmune $\mathrm{CAH}$, by the time of presentation will already have histologic evidence of established cirrhosis on liver biopsy $(1,3,4)$. Because hepatic cirrhosis can be associated with the production of pigment gall stones by the liver $(29,30)$, cases of sclerosing cholangitis could inadvertently be attributed to intrahepatic lithiasis rather than to a primary sclerosing process. Early cholangiography, in a patient with

6. Wiesner RH, LaRusso NF. Clinicopathologic features of the syndrome of primary sclerosing cholangitis. Gastroenterology 1980; 79; 200-6.

7.Soloway RD, Summerskill WH, Baggenstoss AH, et al. Clinical, biochemical and histological remission of severe chronic active liver disease: a controlled study of treatments and early prognosis. Gastroenterology 1972; 63: 820-33.

8. Thomas HC, DeVilliers D, Potter B, et al. Immune complexes in acute and chronic liver diseases. Clin Exp Immunol 1978; 31: 150-7.

9. Bodenheimer HC, LaRusso NF, Thayer WR, et al. Elevated circulating immune complexes in primary sclerosing cholangitis. Hepatology 1983; 3: $150-4$

10. Doniach D, Roitt IM, Walker JG, et al. Tissue antibodies in primary biliary cirrhosis, active chronic (lupoid) hepatitis, cryptogenic cirrhosis and other autoimmune $\mathrm{CAH}$ and cholestatic features or cryptogenic cirrhosis, would likely diminish the frequency with which PSC is overlooked in these pa. tients (5).

The results of a report by Shepherd and colleagues (12) provide indirect evidence that PSC may coexist with autoimmune $\mathrm{CAH}$ more often than has previously been appreciated. In their study, greater than $80 \%$ of chronic ulcerative colitis patients with abnormal liver enzyme tests had chol. angiographic changes consistent with PSC. Thus, a significant portion of patients with chronic ulcerative colitis and autoimmune $\mathrm{CAH}$ would presumably have evidence of PSC, were chol. angiography performed.

Typically, the liver diseases associated with inflammatory bowel disease follow the onset of bowel signs or symptoms. In the two patients described in the present report the opposite was observed. Whether this finding might serve to identify individuals in whom autoimmune $\mathrm{CAH}$ and PSC are likely to coexist remains to be determined. A persistently elevated serum alkaline phosphatase following an otherwise prompt biochemical response to the initiation of corticosteroids might further suggest the coexistence of these disorders (31-33). liver diseases and their clinical implications. Clin Exp Immunol 1966; 1: 237.

11. Jensen DM, McFarlane IG, Portmann BS, et al. Detection of antibodies directed against a liver-specific membrane lipoprotein in patients with acute and chronic active hepatitis. N Engl J Med 1978; 299: 1-7.

12. Shepherd HA, Selby WS, Chapman RWG, et al. Ulcerative colitis and persistent liver dysfunction. Q J Med 1983; 208: 503-13.

13. LaRusso NF, Wiesner RH, Ludwig J, et al. Primary sclerosing cholangitis. N Engl J Med 1984; 310: 899-903.

14. Silva H, Hall E, Hill KR, et al. Renal involvement in active 'juvenile' cirrhosis. J Clin Pathol 1965; 18: 157.

15. Smith MP, Loe RH. Sclerosing cholangitis. Review of recent case reports and associated diseases and four new cases. Am J Surg 1965; 110: 239-46.

16. Viteri AL, Hardin WJ, Dyck WP.

Peyronie's disease, and sclerosing chol- 
angitis in a patient with ulcerative colitis. Am J Dig Dis 1979; 24: 490-1.

17.Eddleston ALWF, Williams R. HLA system and liver disease. In: Popper $\mathrm{H}$, Schaffner F, eds. Progress in Liver Disease, Vol VI. New York: Grune and Stratton, 1979: 285.

18. Schrumpf E, Fausa O, Foore O, et al. HLA antigens and immunoregulatory T cells in ulcerative colitis associated with hepatobiliary disease. Scand J Gastroenterol 1982; 17: 187-91.

19. Alberti-Flor JJ, Jeffers L, Schiff ER. Primary sclerosing cholangitis occurring in a patient with systemic lupus erythematosus and diabetes mellitus. Am J Gastroenterol 1984; 79: 889-91.

20. Ruyon BA, La Brecque DR, Anuras S, et al. The spectrum of liver disease in systemic lupus erythematosis. Am J Med 1980; 69: 187.

21.Schalm SW, Korman MG, Summerskill WHJ, et al. Severe chronic active liver disease: prognostic significance of initial morphologic patterns. Am J Dig Dis 1977; 22: 973-80.
22. Scheuer PJ. Chronic hepatitis. In: Liver Biopsy Interpretation, 3rd edn. London: Bailliere Tindall, 1981: 102. 17.

23. Wright EC, Seef LB, Berk PD, et al. Treatment of chronic active hepatitis: an analysis of three controlled trials. Gastroenterology 1977; 73: 1422-30.

24. Thorpe MEC, Sheuer PJ, Sherlock S. Primary sclerosing cholangitis, the biliary tract and ulcerative colitis. Gut 1967;8: 435.

25. Danzi JT, Makipour H, Farmer RG. Primary sclerosing cholangitis. A report of nine cases and clinical review. Am J Gastroenterol 1976; 64: 109-16.

26. Scheuer PJ. Biliary disease and cholestasis. In: Liver Biopsy Interpretation. London: Bailliere Tindall, 1981: 36-60.

27. Kirk AP, Jain S, Pocock S, et al. Late results of Royal Free Hospital controlled trial of prednisolone therapy in hepatitis B surface antigen-negative chronic active hepatitis. Gut 1980; 21: 78-83.
28. Tan EGC, Warren KW. Diseases of the gallbladder and bile ducts. In: Schiff L, Schiff ER, eds. Diseases of the Liver. Philadelphia: J.P. Lippincott Co, 1982: 1507-59.

29. Bouchier IAD. Postmortem study of the frequency of gallstones in patients with cirrhosis of the liver. Gut 1969; 10: 705-10.

30. Nicholas P, Rinaudo PA, Conn HO. Increased incidence of cholelithiasis in Laennce's cirrhosis: a postmortem evaluation of pathogenesis. Gastroenterology 1972; 63: 112-21.

31. Schrumpf E, Elgjo K, Fausa O, et al. Sclerosing cholangitis in ulcerative colitis. Scand J Gastroenterol 1980; 15: 689-97.

32. Perret AD, Higgins $G$, Johnston $\mathrm{HH}$, et al. The liver in ulcerative colitis. QJ Med 1971; 40: 211-38,

33. Olson R, Halten L. Concurrence of ulcerative colitis and chronic active hepatitis - clinical course and result of colectomy. Scand J Gastroenterol 1975; 10: 331-4. 


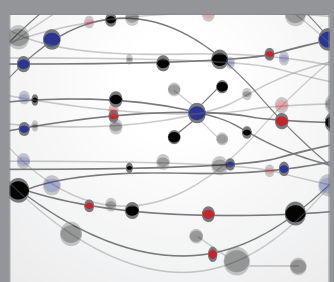

The Scientific World Journal
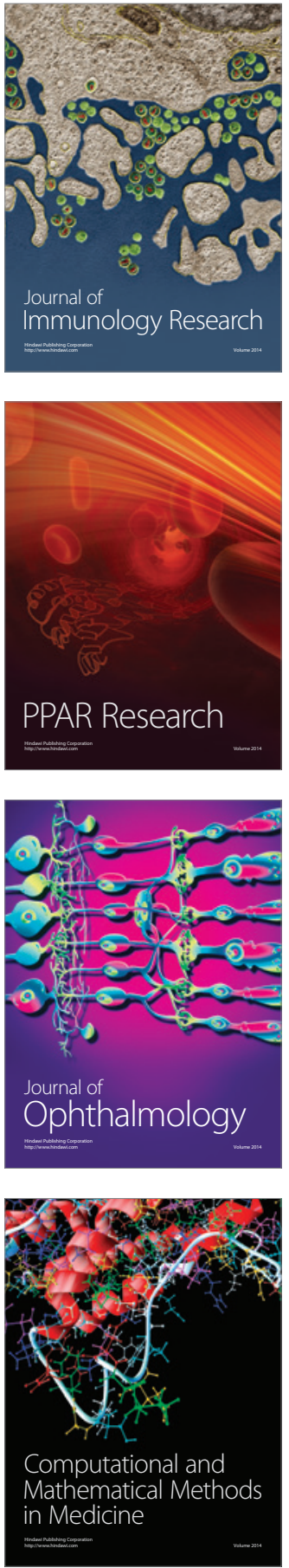

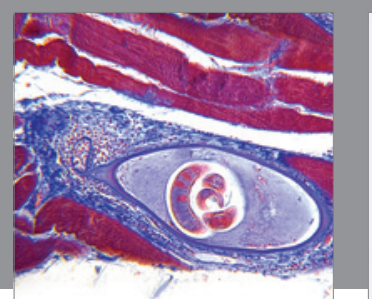

Gastroenterology Research and Practice

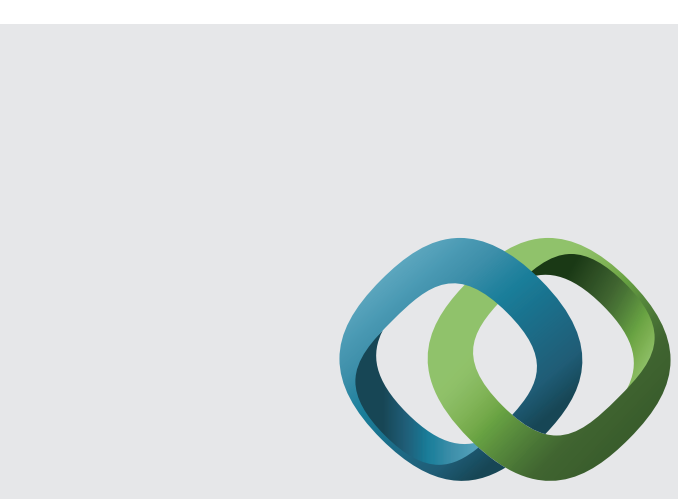

\section{Hindawi}

Submit your manuscripts at

http://www.hindawi.com
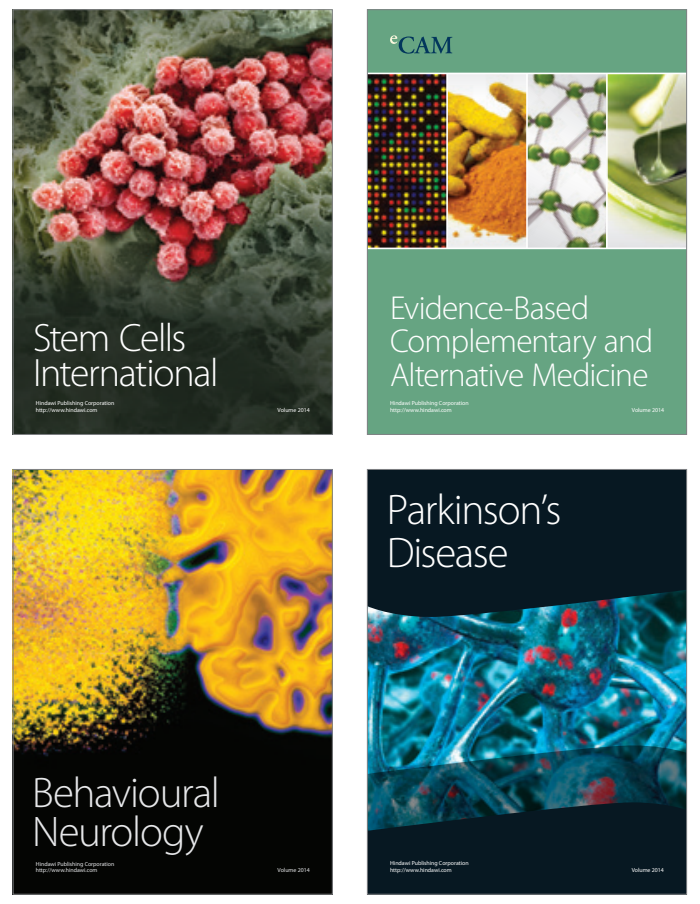
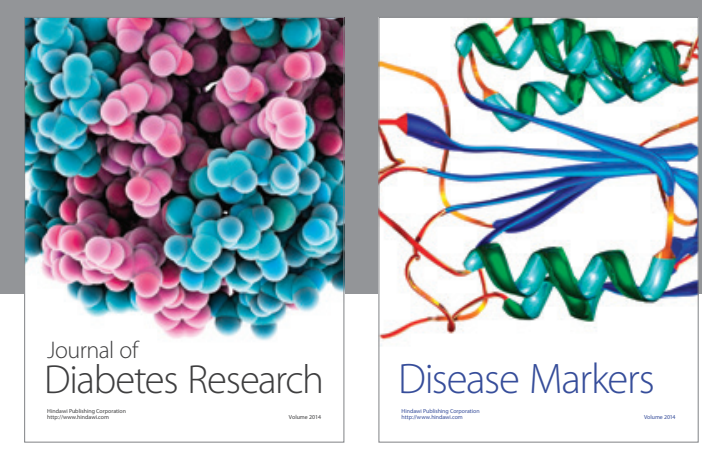

Disease Markers
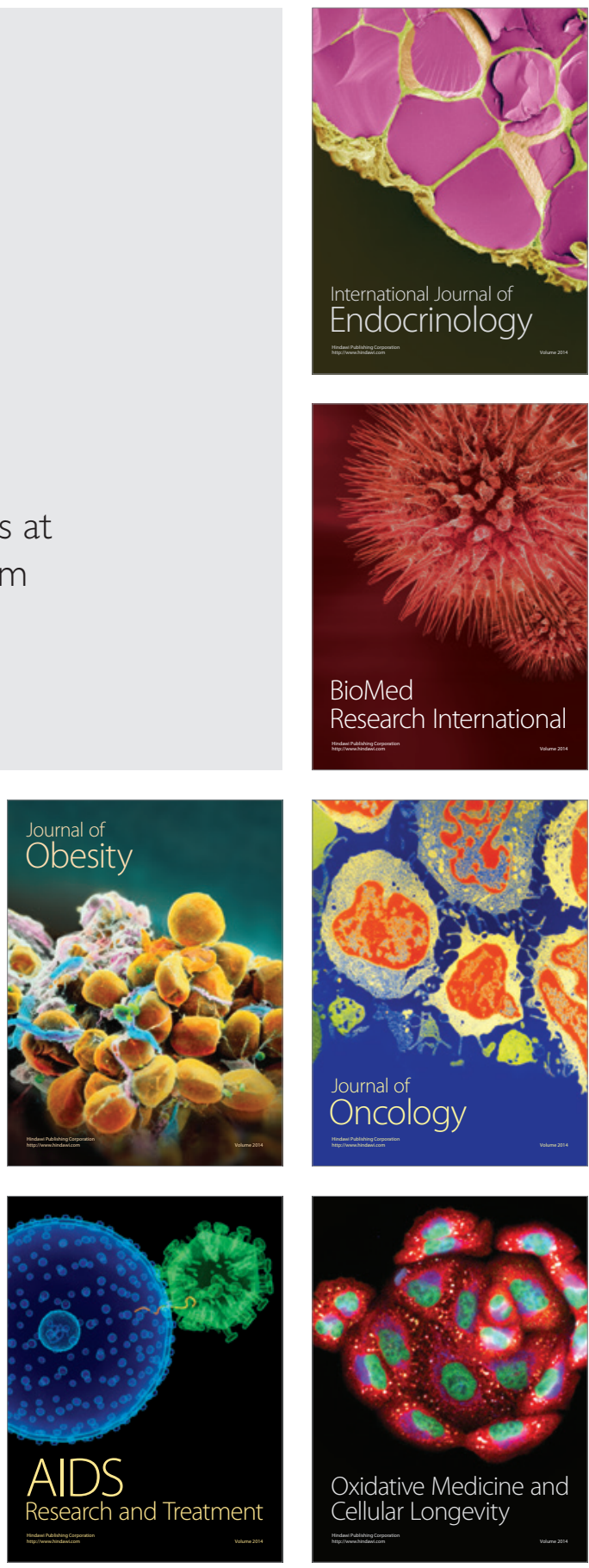